\title{
Effect of molybdenum on structure, microstructure and mechanical properties of biomedical Ti-20Zr-Mo alloys
}

\author{
Pedro Akira Bazaglia Kuroda a,b, Marília Afonso Rabelo Buzalaf ${ }^{\mathrm{c}}$, Carlos Roberto Grandini a,b,* \\ a UNESP - Univ Estadual Paulista, Laboratório de Anelasticidade e Biomateriais, 17.033-360, Bauru, SP, Brazil \\ b IBTN/Br - Institute of Biomaterials, Tribocorrosion and Nanomedicine, Brazilian Branch, 17.033-360 Bauru, SP, Brazil \\ c USP - Universidade de São Paulo, Departamento de Ciências Biológicas, 17.012-901, Bauru, SP, Brazil
}

\section{A R T I C L E I N F O}

Article history:

Received 22 December 2015

Received in revised form 26 April 2016

Accepted 12 May 2016

Available online 13 May 2016

\section{Keywords:}

Titanium alloys

Microstructure

Biomaterial

\begin{abstract}
A B S T R A C T
Titanium has an allotropic transformation around $883^{\circ} \mathrm{C}$. Below this temperature, the crystalline structure is hexagonal close-packed ( $\alpha$ phase), changing to body-centered cubic ( $\beta$ phase). Zirconium has the same allotropic transformation around $862{ }^{\circ} \mathrm{C}$. Molybdenum has body-centered cubic structure, being a strong $\beta$-stabilizer for the formation of titanium alloys. In this paper, the effect of substitutional molybdenum was analyzed on the structure, microstructure and selected mechanical properties of Ti-20 Zr-Mo (wt\%) alloys to be used in biomedical applications. The samples were prepared by arc-melting and characterized by x-ray diffraction with subsequent refinement by the Rietveld method, optical and scanning electron microscopy. The mechanical properties were analyzed by Vickers microhardness and dynamic elasticity modulus. X-ray measurements and Rietveld analysis revealed the presence of $\alpha^{\prime}$ phase without molybdenum, $\alpha^{\prime}+\alpha^{\prime \prime}$ phases with $2.5 \mathrm{wt} \%$ of molybdenum, $\alpha^{\prime \prime}+\beta$ phases with 5 and $7.5 \mathrm{wt} \%$ of molybdenum, and only $\beta$ phase with $10 \mathrm{wt} \%$ of molybdenum. These results were corroborated by microscopy results, with a microstructure composed of grains of $\beta$ phase and lamellae and needles of $\alpha^{\prime}$ and $\alpha^{\prime \prime}$ phase in intra-grain the region. The hardness of the alloy was higher than the commercially pure titanium, due to the action of zirconium and molybdenum as hardening agents. The samples have a smaller elasticity modulus than the commercially pure titanium.
\end{abstract}

(c) 2016 Elsevier B.V. All rights reserved.

\section{Introduction}

In the development of orthopedic prostheses are used metallic materials as stainless steel, chromium-cobalt-based alloys, commercially pure titanium and titanium alloys [1,2]. Metallic biomaterials are used mainly in replacement of parts of the body such as orthopedic prostheses, dental implants and cardiovascular applications.

Commercially pure titanium is currently the most attractive metallic material for biomedical applications [2]. However, despite having excellent corrosion resistance, this element has no mechanical properties suitable to be used as prosthesis. Thus, several of its properties can be improved with the addition of substitutional and interstitial elements, and thermomechanical processing techniques [3,4].

The most widely used titanium alloy for biomedical applications is the Ti-6Al-4V [1]. However, studies have shown that vanadium causes allergic reactions in human tissue [5] and aluminum has been associated with neurological disorders [6]. So, to work around this problem, new titanium alloys without the presence of these elements are being

\footnotetext{
* Corresponding author at: UNESP - Univ Estadual Paulista, Laboratório de Anelasticidade e Biomateriais, 17.033-360, Bauru, SP, Brazil.

E-mail address: betog@fc.unesp.br (C.R. Grandini).
}

processed and studied, with the addition of different elements, usually the $\beta$-stabilizers, that change its microstructure and mechanical properties, which may make these materials more promising for biomedical use. The most suitable metals as an alloying element in this case are niobium, zirconium, molybdenum and tantalum [7].

Titanium is a transition metal that has an allotropic transformation around $883^{\circ} \mathrm{C}$ ( $\beta$ transus). Below this temperature, its crystalline structure is hexagonal compact ( $\alpha$ phase). This element has a body-centered cubic structure ( $\beta$ phase), being formed at temperatures above $\beta$ transus, remaining stable until the metal melting. This characteristic offers the possibility to obtain alloys with microstructures of $\alpha, \beta$ or $\alpha / \beta$ type, depending on the elements that stabilize either phase [8].

Zirconium has an allotropic transformation around $862{ }^{\circ} \mathrm{C}$. Below this temperature, its crystalline structure is hexagonal compact $(\alpha$ phase) and above this temperature has a body-centered cubic structure ( $\beta$ phase) [9]. This element is considered neutral to form alloys with titanium. However, it decreases the initial temperature of martensitic $\alpha^{\prime}$ transformation [10], and in the presence of another $\beta$ stabilizer element, it has $\beta$ stabilizer actuation [11].

Molybdenum has body-centered cubic crystalline structure. In small amounts, it is applied in several alloys for hardening and make them corrosion resistant. The addition of molybdenum decreases the $\beta$ transus temperature of titanium [12]. 
Table 1

EDS analysis of the elements that compose Ti-20Zr-Mo alloys.

\begin{tabular}{llll}
\hline Samples & Ti (wt\%) & Zr (wt\%) & Mo (wt\%) \\
\hline Ti-Zr & $78.1 \pm 0.1$ & $21.9 \pm 0.2$ & - \\
Ti-20Zr-2.5Mo & $76.3 \pm 0.1$ & $21.0 \pm 0.1$ & $2.6 \pm 0.1$ \\
Ti-20Zr-5Mo & $71.2 \pm 0.1$ & $22.8 \pm 0.1$ & $5.8 \pm 0.1$ \\
Ti-20Zr-7.5Mo & $71.1 \pm 0.1$ & $20.9 \pm 0.1$ & $7.9 \pm 0.1$ \\
Ti-20Zr-10Mo & $66.2 \pm 0.1$ & $22.4 \pm 0.1$ & $11.4 \pm 0.1$ \\
\hline
\end{tabular}

As the physical properties of metals and alloys are strongly influenced by the presence of interstitial and substitutional solutes and taking into consideration the suitable conditions of Ti-Zr and Ti-Mo alloys for biomedical applications, the formation of ternary alloys of Ti-ZrMo system can present the most interesting properties for the biomedical area, such as the reduction of the elasticity modulus. Thus, the objective of this paper is to analyze the influence of molybdenum substitutional solute on structure, microstructure and selected mechanical properties (microhardness and elastic modulus) of ternary alloys of Ti-20Zr-Mo system.

\section{Materials and methods}

It were used as starting materials commercially pure titanium $(99.8 \%$ purity, Sandinox), in the shape of a cylindrical bar; zirconium ( $99.8 \%$ purity, Aldrich) blade-shaped and molybdenum (99.9\% purity, Interchnik) in the form of wire. The melting was carried out using an arc-melting furnace, with water cooled copper crucible and controlled argon atmosphere. All ingots were melted five times to ensure complete homogeneity.

To verify the chemical composition, stoichiometry and homogeneity of samples it were carried out analyses of composition using energy dispersive spectroscopy (EDS) (Oxford, INCA model) and density measures based on the Archimedes principle, being used an analytical precision balance (Ohaus, Explorer model).

For structural analysis, X-ray diffraction measurements (Rigaku, D/ Max-2100PC model) were performed. The used method to obtain the diffractograms was the powder method, with $\mathrm{Cu}-\mathrm{K}_{\alpha}$ radiation $(\lambda=$ $1.544 \AA$ ), $20 \mathrm{~mA}$ current, potential of $40 \mathrm{kV}$, time of $3.2 \mathrm{~s}$, range of $20^{\circ}$ to $100^{\circ}$ and step of $0.02^{\circ}$, in the fixed time mode. Quantitative analysis of phases was carried out by Rietveld's method using the GSAS®

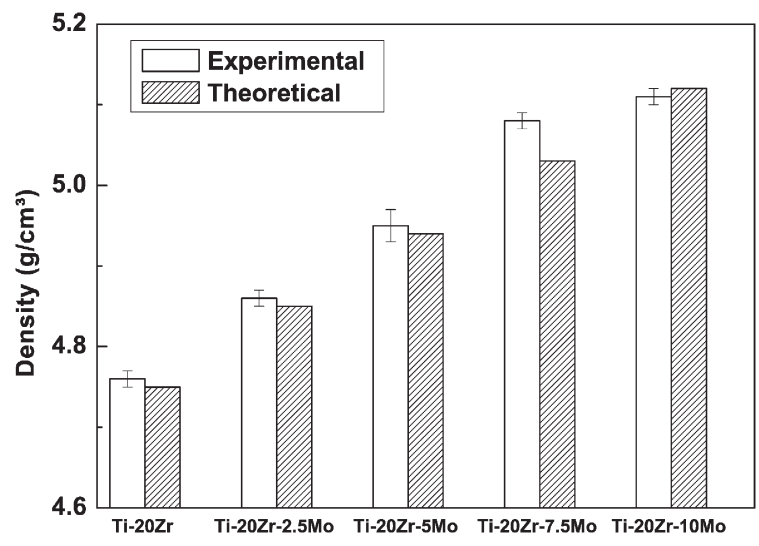

Fig. 2. Density of Ti-20Zr-Mo alloys.

software, with crystallographic sheets from ICSD database [13] and the results suggested by Banumathy et al. [14].

Before the microstructural analysis, samples were submitted to standard metallographic preparation, using sandpaper and chemical etching by acid solution of $\mathrm{HNO}_{3}, \mathrm{HF}$ and $\mathrm{H}_{2} \mathrm{O}$ (15:5:80) [15]. Images were obtained using an optical microscope (Olympus, BX51M model) and a scanning electron microscope (Carl Zeiss, EVO-015 model).

For hardness measurements it was used a microhardness tester (Shimadzu, HMV-2 model). In each sample, twenty indentations were made, with $25 \mathrm{~g}$ load in a time of $60 \mathrm{~s}$. The results were analyzed using ANOVA test.

For the dynamical elastic modulus measurements, it was used the impulse excitation technique (ATCP, Sonelastic ${ }^{\circledR}$ model).

\section{Results and discussion}

Table 1 presents the results of quantitative analysis by EDS and in Fig. 1 are shown the mappings of the distribution of elements that compose the alloys. Titanium is represented by red color, zirconium by green color and molybdenum by blue color. There is a good distribution, indicating that the procedure performed a sample well homogeneous, without the presence of aggregates or segregates.

Fig. 2 shows the values for the density of samples of alloys of Ti-20ZrMo system, after melting. The results show little difference between

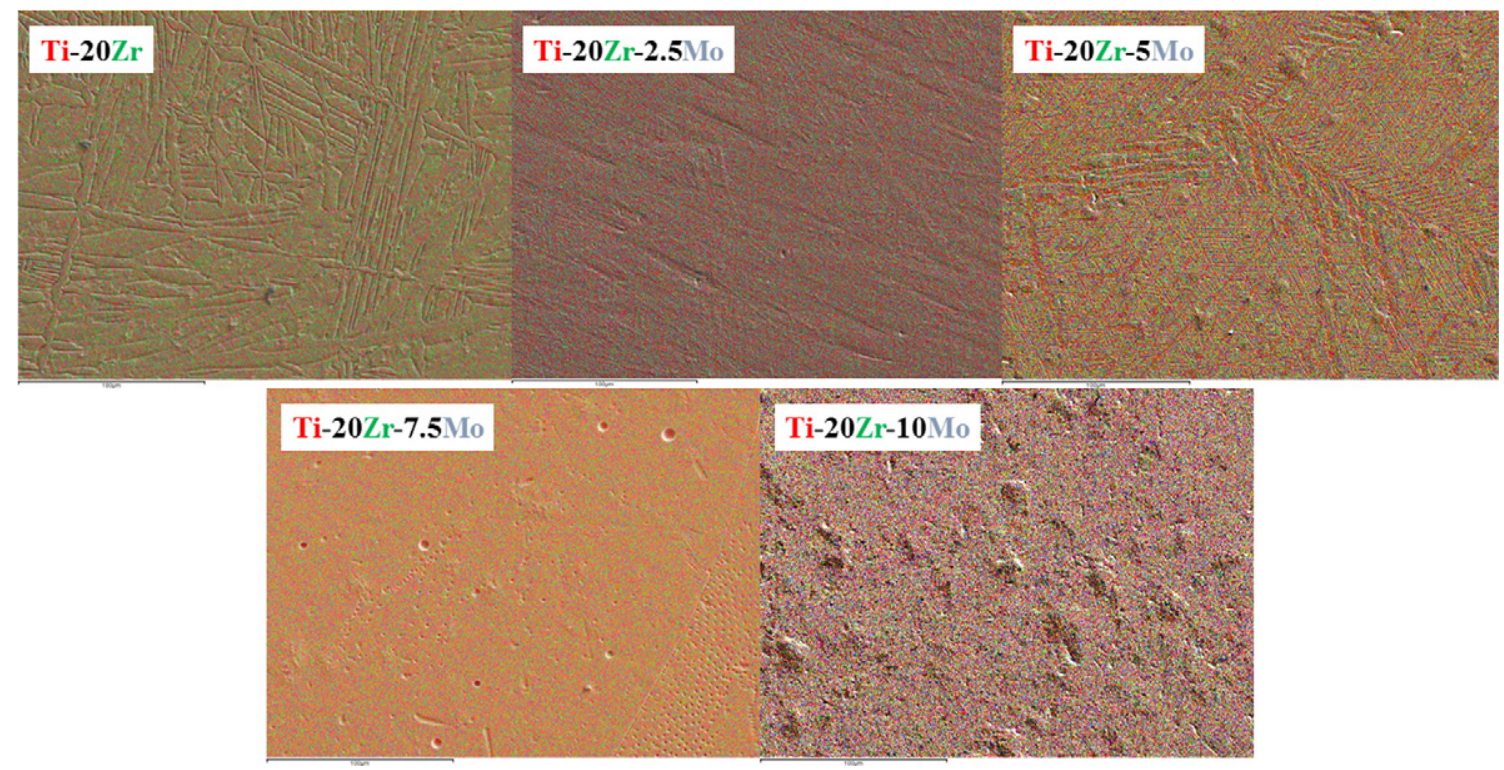

Fig. 1. Chemical mapping, by EDS, for the samples of the alloys of Ti-20Zr-Mo system, after melting. 


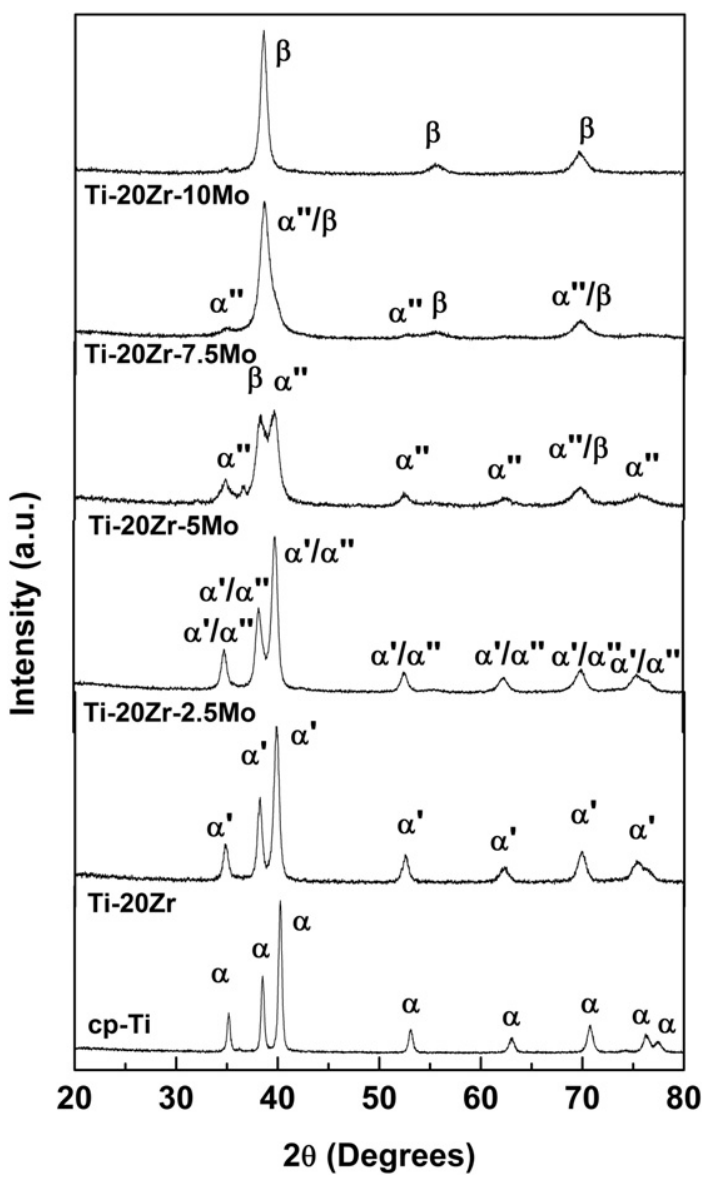

Fig. 3. X-ray diffractograms for the samples of Ti-20Zr-Mo alloys, in comparison to cp-Ti.

experimental and theoretical values, indicating that the composition of the alloys is close to stoichiometric values. It is observed that the value of the alloys density increased compared with the value of the density of pure titanium, because the density of molybdenum $\left(10.23 \mathrm{~g} / \mathrm{cm}^{3}\right)$ and zirconium $\left(6.51 \mathrm{~g} / \mathrm{cm}^{3}\right)$ are higher than titanium $\left(4.43 \mathrm{~g} / \mathrm{cm}^{3}\right)$, thus providing an increase in the value of the density.

Fig. 3 shows a comparison of the $\mathrm{x}$-ray diffraction patterns for samples of Ti-20Zr-Mo alloys. After melting, the base alloy, Ti-20Zr, presented only the peaks representing the martensitic $\alpha^{\prime}$ phase, with distorted hexagonal structure. The alloy with $2.5 \mathrm{wt} \%$ of molybdenum, also presented martensitic $\alpha^{\prime}$ phase peaks, but $\alpha^{\prime \prime}$ phase peaks, with orthorhombic structure, were observed. With 5 and $7.5 \mathrm{wt} \%$ of

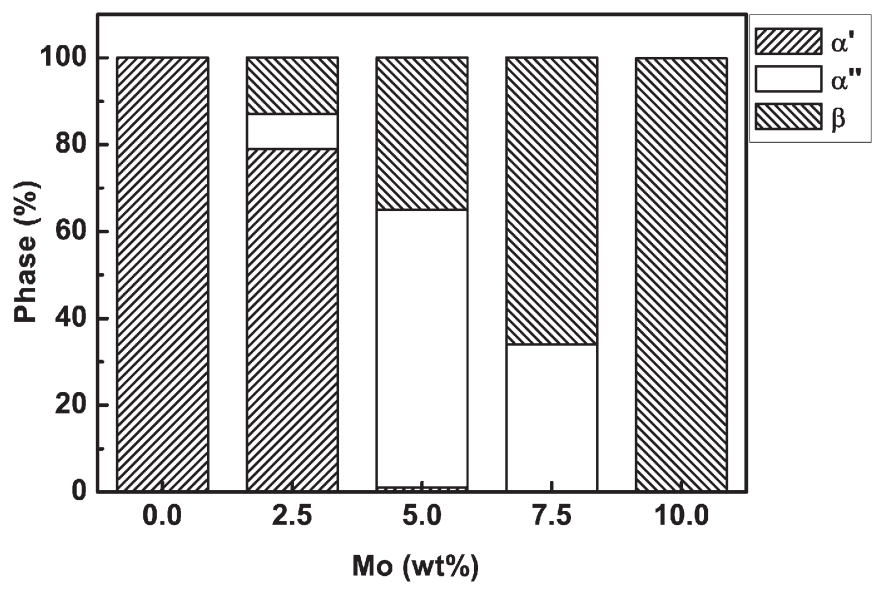

Fig. 4. Phase distribution in the Ti-20Zr-Mo alloys. molybdenum, the alloys showed peaks of martensitic $\alpha$ " phase and $\beta$ phase, with body-centered cubic crystalline structure. Finally, the alloy with $10 \mathrm{wt} \%$ of molybdenum presented only peaks that characterize the $\beta$ phase.

Molybdenum is a strongly $\beta$-stabilizer and that stabilizes completely $\beta$-phase with levels above $10 \mathrm{wt} \%$ [12]. The authors observed that with $6 \mathrm{wt} \%$ of molybdenum a small amount of $\alpha^{\prime \prime}$ phase begins to form and above $9 \mathrm{wt} \%$ of molybdenum, a significant amount of $\beta$ phase was present. It can be observed that the presence of $\beta$-stabilizer elements made zirconium a non-neutral element and pass to act on stabilizing $\beta$-phase in the alloy [11,15]. Peaks of $\alpha^{\prime \prime}$ phase in Ti-20Zr-2.5Mo and presence of peaks from the $\beta$ phase in Ti-20Zr-5Mo and Ti-20Zr-7.5Mo alloys are related to the action of zirconium, which together with another $\beta$-stabilizer element (in the case molybdenum), acts on $\beta$-transus temperature decreases.
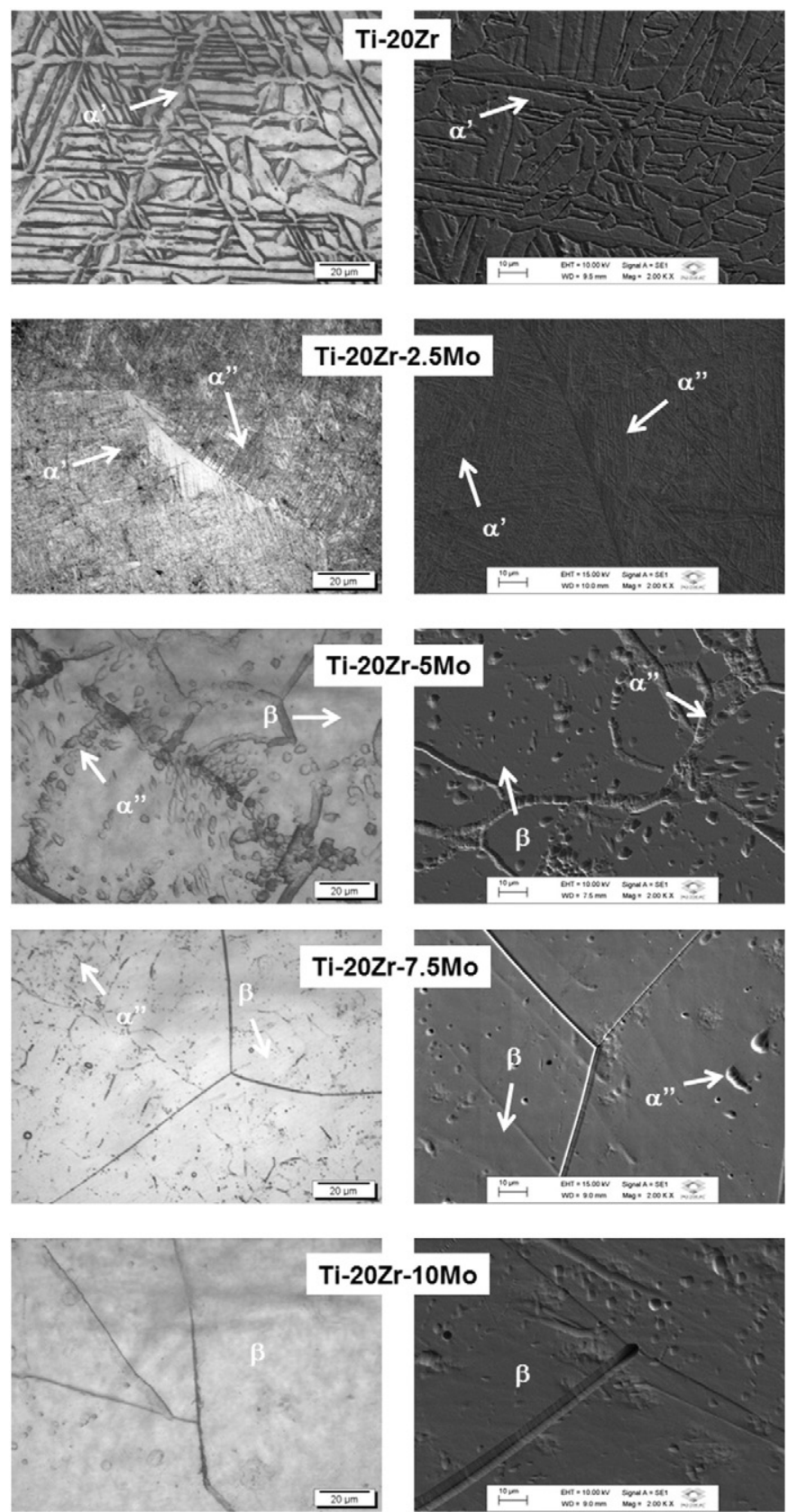

(a)

(b)

Fig. 5. Micrographs of the samples of Ti-20Zr-Mo, obtained by optical (a) and scanning electron microscopy (b) 


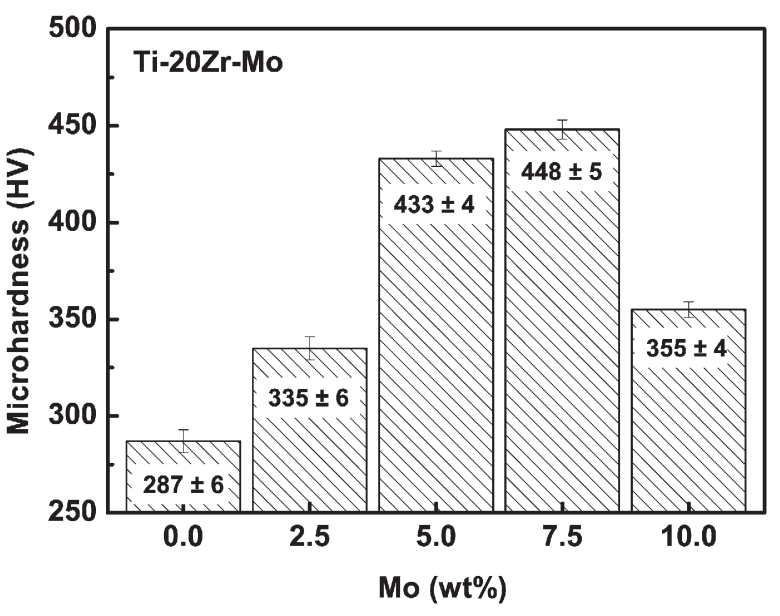

Fig. 6. Microhardness for the samples of Ti-20Zr-Mo alloys.

Fig. 4 shows the quantitative phases analysis obtained by structural refinement of X-ray diffractograms using the Rietveld's method. It can be observed that Ti-20Zr presented only the formation of $\alpha^{\prime}$ phase. Already Ti-20Zr-2.5Mo alloy presented three-phase coexistence, $\alpha^{\prime}$ with approximately $79 \% ; \alpha^{\prime \prime}$, with approximately $7 \%$ and $\beta$, with $13 \%$. The results for Ti-20Zr-5Mo and Ti-20Zr-7.5Mo alloys showed two-phase coexistence, $\alpha^{\prime \prime}$ with $60 \%$ and $\beta$, with $40 \%$ for the alloy with $5 \mathrm{wt} \%$ of molybdenum and $35 \%$ of $\alpha^{\prime \prime}$ phase and $65 \%$ of the $\beta$ phase, to alloy with $7.5 \mathrm{wt} \%$ of molybdenum. Finally, Ti-20Zr-10Mo just presented only the $\beta$ phase.

Fig. 5 shows the micrographs obtained for optical and scanning electron microscopy. It can be observed that the microstructure of $\mathrm{Ti}-20 \mathrm{Zr}$ is composed of acicular structures (Widmanstätten pattern), typical of martensitic $\alpha^{\prime}$ phase. In the case of Ti-20Zr-25Mo, it is observed that the microstructure consists of thicker needles, which are typical of $\alpha^{\prime}$ phase, and thinner needles, typical of $\alpha^{\prime \prime}$ phase. For Ti-20Zr-5Mo and Ti-20Zr-7.5Mo alloys, the micrographs showed small needles characteristics of martensitic $\alpha^{\prime}$ phase and $\beta$ phase matrix, showing clearly the grain boundaries. Finally, Ti-20Zr-10Mo alloy presents only the morphology characteristic of $\beta$ phase. All the images corroborate the experimental results of $x$-ray diffraction.

By means of Figs. 3 to 5 it can be clearly seen the $\beta$-stabilizing action of molybdenum, because its inclusion in Ti-20Zr system alloys decreases gradually the percentages of $\alpha^{\prime}$ phase and increases quickly the percentage of $\beta$ phase $[10,12]$.

Fig. 6 shows the values of hardness as a function of molybdenum concentration, for samples of Ti-20Zr-Mo alloys. All studied alloys remained with hardness values above $\mathrm{cp}-\mathrm{Ti}$, due to solid solution

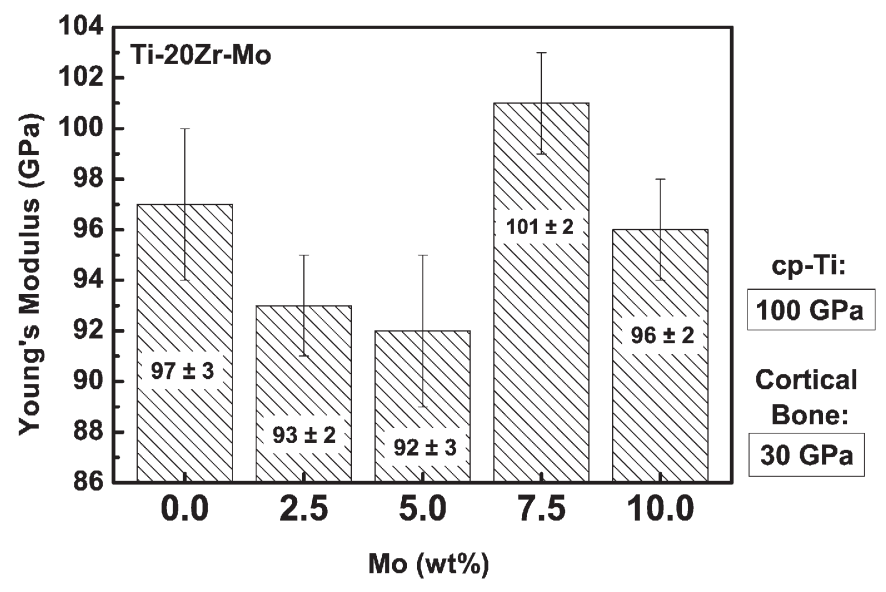

Fig. 7. Elastic modulus for the samples of Ti-20Zr-Mo alloys. hardening caused by the addition of zirconium and molybdenum [15]. Ti-20Zr alloy showed lower hardness because has not the element molybdenum in its composition. Ti-20Zr-2.5Mo and Ti-20Zr-5Mo alloys, presented higher values of hardness than Ti-20Zr alloy, because with the increased of molybdenum content there was an increase of hardness due to the formation of $\alpha^{\prime \prime}$ phase, that have higher hardness than $\alpha^{\prime}$ phase. In Ti-20Zr-7.5 Mo, despite the decrease $\alpha^{\prime \prime}$ phase and increase in $\beta$ phase, the increase in the hardness may have occurred possibly due to precipitation of $\omega$ phase in these alloys [16]. In the case of Ti-20Zr$10 \mathrm{Mo}$, it can be observed a decrease in hardness value, due to increase in $\beta$-phase, which has the lowest value of hardness among the phases present in this system.

The elastic modulus is strongly influenced by the crystalline structure, because the module of alloys with more than one phase is determined by the volume fraction of each constituent phase [1]. The higher the bonding force between atoms, the higher the elastic modulus, and the atomic bonding strength is inversely proportional to the volume of the unit cell. Therefore, the smaller the volume of the unit cell, the higher the elastic modulus of the material. Fig. 7 shows the results of the dynamic elastic modulus as a function of molybdenum content, for the samples of Ti-20Zr-Mo alloys system, where it can be observed that the addition of molybdenum affected the elastic modulus of the alloys. The elastic modulus features initially a small decrease for the alloy with Ti-20Zr to the alloy with $2.5 \mathrm{wt} \%$ of molybdenum, due to the formation of martensitic $\alpha^{\prime}$ phase, until it reaches a minimum with the formation of martensitic $\alpha^{\prime \prime}$ phase. From $5 \mathrm{wt} \%$ of molybdenum it is observed a rise in the modulus, possibly attributed to the formation of metastable $\omega$ phase. From $7.5 \mathrm{wt} \%$ of molybdenum is observed a trend of decline in the value of the elastic modulus, assigned to the formation of the $\beta$ phase. Note that the majority of alloys have the elastic modulus less than $\mathrm{cp}$-Ti and higher than cortical bone (around $30 \mathrm{GPa})[1]$.

The volume of the unit cell of studied alloys decreases with the addition of molybdenum in the three phases present, however, those where the $\alpha^{\prime \prime}$ phase is present have lower elastic modulus due to its low atomic packing factor and unit cell volume larger than those of other phases [17].

\section{Conclusions}

From the results presented in this paper it is possible to conclude that the melting of the alloys was successful, reaching the stoichiometry originally proposed.

The results of structural and microstructural analyses of studied alloys showed that the microstructure of Ti-20Zr is formed by the $\alpha^{\prime}$ phase; of Ti-20Zr-2.5Mo alloy is formed by the coexistence of martensitic $\left(\alpha^{\prime}\right.$ and $\left.\alpha^{\prime \prime}\right)$ and $\beta$ phases; of Ti-20Zr-5Mo and Ti-20Zr-7.5Mo alloys, are formed by martensitic $\alpha^{\prime \prime}$ and $\beta$ phases and of Ti-20Zr-10Mo is formed only by the $\beta$ phase, showing the $\beta$-stabilizer effect of molybdenum.

The results of microhardness and elastic modulus had a similar behavior with the addition of molybdenum. The hardness of the alloys increased with $7.5 \mathrm{wt} \%$ of molybdenum due to a possible $\omega$ phase precipitation. In alloys with $10 \mathrm{wt} \%$ a small decrease in hardness was observed due to the stabilization of the $\beta$ phase. The materials have higher hardness than the $\mathrm{cp}-\mathrm{Ti}$, caused by solid solution hardening of the alloy.

The studied alloys exhibit elastic modulus similar to cp-Ti. Ti-20Zr5 Mo has the better elastic modulus, due to presence of $\alpha^{\prime \prime}$ phase, that has lower elastic modulus than $\alpha^{\prime}$ phase.

\section{Acknowledgements}

The authors thank Brazilian agencies Capes, CNPq (grants \#481313/ 2012-5 and \#307.279/2013-8) and FAPESP (grant \# 2012/22.742-6) for their financial support. 


\section{References}

[1] M. Geetha, A.K. Singh, R. Asokamani, A.K. Gogia, Prog. Mater. Sci. 54 (2009 397-425.

[2] D. Banerjee, J.C. Williams, Acta Mater. 61 (2013) 844-879.

[3] M. Long, H.J. Rack, Biomaterials 19 (1998) 1621-1639.

[4] M. Niinomi, J. Mech. Behav. Biomed. Mater. 1 (2008) 30-42.

[5] E. Eisenbarth, D. Velten, M. Müller, R. Thull, J. Breme, Biomaterials 25 (2004) 5705-5713.

[6] D.R.C. McLachlan, Environmetrics 6 (1995) 233-275.

[7] Y. Li, C. Yang, H. Zhao, S. Ou, X. Li, Y. Li, Materials 7 (2014) 1709-1800.

[8] H.J. Rack, J.I. Qazi, Mater. Sci. Eng. C 26 (2006) 1269-1277.

[9] W.-F. Ho, W.-K. Chen, S.-C. Wu, H.-C. Hsu, J. Mater. Sci. Mater. Med. 19 (2008) 3179-3186.
[10] C. Leyens, M. Peters, Titanium and Titanium Alloys: Fundamentals and Applications, Wiley-VCH, New York, 2005.

[11] D.R.N. Correa, F.B. Vicente, R.O. Araújo, M.L. Lourenço, P.A.B. Kuroda, M.A.R. Buzalaf, C.R. Grandini, Journal of Materials Research and Technology 4 (2015) 180-185.

[12] W.F. Ho, C.P. Ju, J.H. Chern Lin, Biomaterials 20 (1999) 2115-2122.

[13] ICSD, Inorganic Crystal Structure Database, http://icsd.ill.eu/icsd/index.php2014.

[14] S. Banumathy, R.K. Mandal, A.K. Singh, J. Appl. Phys. 106 (2009) 093518.

[15] W.-F. Ho, S.-C. Wu, S.-K. Hsu, Y.-C. Li, H.-C. Hsu, Mater. Sci. Eng. C 32 (2012) 517-522.

[16] G. Lütjering, J.C. Williams, Titanium, second ed. Spinger, Berlim, 2007.

[17] Y.L. Zhou, M. Niinomi, T. Akahori, Mater. Sci. Eng. A 371 (2004) 283-290. 